\title{
AN INEXPENSIVE UPGRADE OF OLDER LIQUID SCINTILLATION EQUIPMENT FOR RADIOCARBON DATING
}

\author{
DAVID C STEINKE and ROBERT M KALIN \\ Department of Geosciences, University of Arizona, Tucson, Arizona 85721
}

\begin{abstract}
We have replaced the original control electronics and added remote computer control to our Packard Instrument Tri-Carb 460C LSC. The total cost of materials to achieve this was $<\$ 1200$; ca $200 \mathrm{hr}$ were spent on design and programming, and installation was complete in $30 \mathrm{~min}$. Our system has spectral analysis in $1 / 2 \mathrm{Kev}$ resolution utilizing the existing 4096 channel multi-channel analyzer, and user-friendly error checking for the mechanical systems. The computer collects spectral information, saves two channels of raw data, plots spectral information and produces data files of the standards, backgrounds and samples used in LOTUS to calculate the age of the sample.
\end{abstract}

\section{INTRODUCTION}

The purpose of this project was to control a Packard 460C Liquid Scintillation Counter (LSC) with a remote microcomputer and gain access to the raw spectrum information for better sample monitoring (Fig 1 ). The use of computers for data reduction and analysis has been investigated (Glass \& Woods, 1970; Williams \& Cope, 1970; Spratt, 1972; Stanley, 1972, 1976; Bowyer \& Pearson, 1973). Gordon et al (1976) have shown that the interface of a multi-channel analyzer (MCA) with a liquid scintillation spectrometer enables the operator to monitor sample quality through spectral analysis. Recent LSC systems have been designed extensively using microcomputer and MCA technology (Polach et al, 1983b, 1984a, 1987; Noakes \& Valenta, 1989).

An older, somewhat IBM-compatible, Sanyo 555 microcomputer was used as the remote computer to keep the cost of this project down. The new 460C interface electronics were constructed by the Department of Geosciences' electronics shop using wire wrapping construction. A video monitor interface board was purchased to drive the monitor, which was part of the $460 \mathrm{C}$. There was no attempt made at the time to improve resolution by changing shielding, anticoincidence or efficiency of photon pickup. The original sample changer mechanics, photomultiplier tubes, preamplifiers, power supplies, pulse detection and A/D conversion electronics were used. The new interface attached to the old connectors. The only part replaced was the Multibus computer assembly.

Since the LSC was in use counting samples, down-time for the installation had to be kept to a minimum. The LSC was out of commission twice, once for testing control signals and timing, and again for the installation; in each instance, the LSC was down for a day. The interface board was constructed, the assembly language program for the interface and the data acquisition/file manager program on the Sanyo were written during a 3month period. The interface was installed and collected data in parallel with the original MCA electronics to ensure that no differences in data collection were occurring. 


\section{SYSTEM BLDCK DIAGRAM}

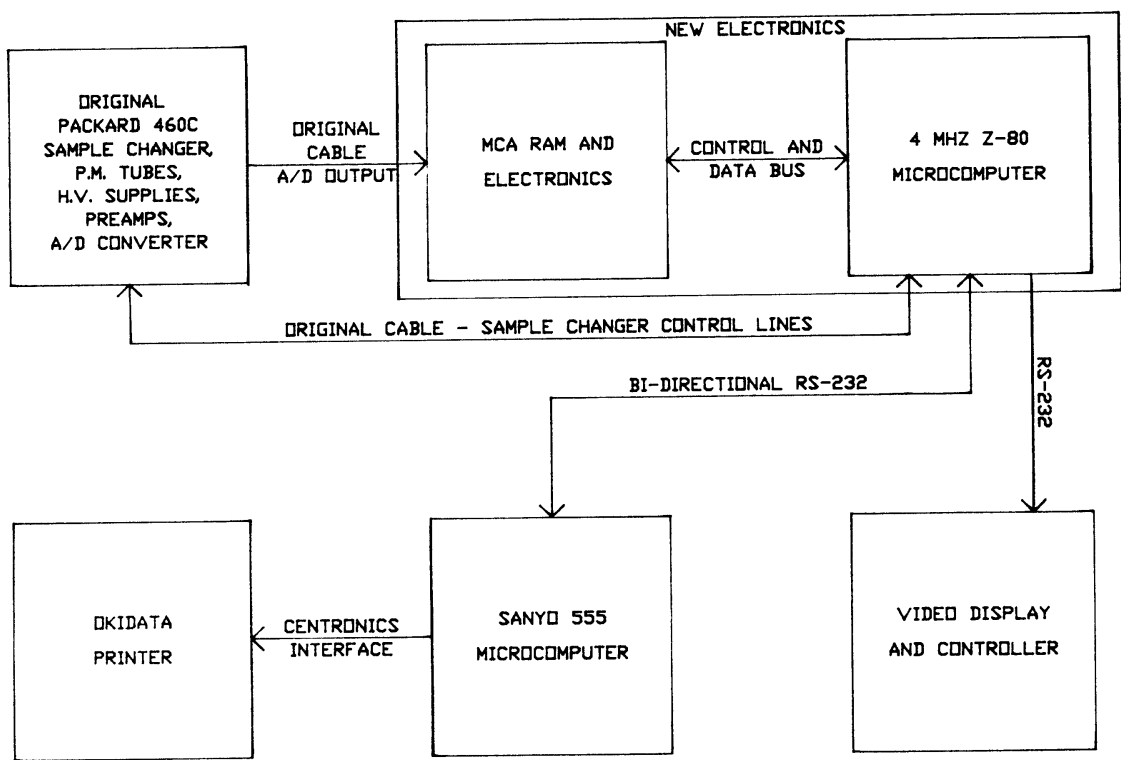

Fig 1. Block diagram of liquid scintillation system

\section{SYSTEM DESCRIPTION}

The upgrade consisted of two main parts, the Sanyo 555 microcomputer, and the replacement interface for the Multibus computer. The Sanyo is a MS-DOS 8088 microcomputer configured with two $5^{1 / 1}{ }^{\prime \prime}$ floppy disk drives, 256k of RAM, a parallel and a serial port. It is not hardware or graphics compatible with IBM. The program for communicating with the LSC interface, handling $\mathrm{I} / \mathrm{O}$, and performing initial statistical analysis was written in Desmet C V2.51. The printout for counting intervals, statistical output, and spectra is on an Okidata ML 84 printer. Routines to display and print spectral information were written in 8088 assembly language and linked to the main program.

The LSC interface consisted of three main parts: CPU, MCA interface and video display interface. A $4 \mathrm{MHZ}$ Z-80 microprocessor, $8 \mathrm{~K}$ byte of ROM, 8K byte of RAM, programmable interval timer and two RS-232 serial ports made up the CPU. One serial port communicates with the Sanyo and the other drives a video display board. The video display shows count time, hardware status and CPMs. The hardware status indication also gives a text error explanation when errors occur in the hardware. The original keyboard and printer on the $460 \mathrm{C}$ were disabled.

The MCA interface (Fig 2) expanded the original memory capacity of the 460C. The new MCA stores 4096 distinct channels with each channel having the capacity of $4.3 \times 10^{9}$ counts. The logic was reworked so that the 


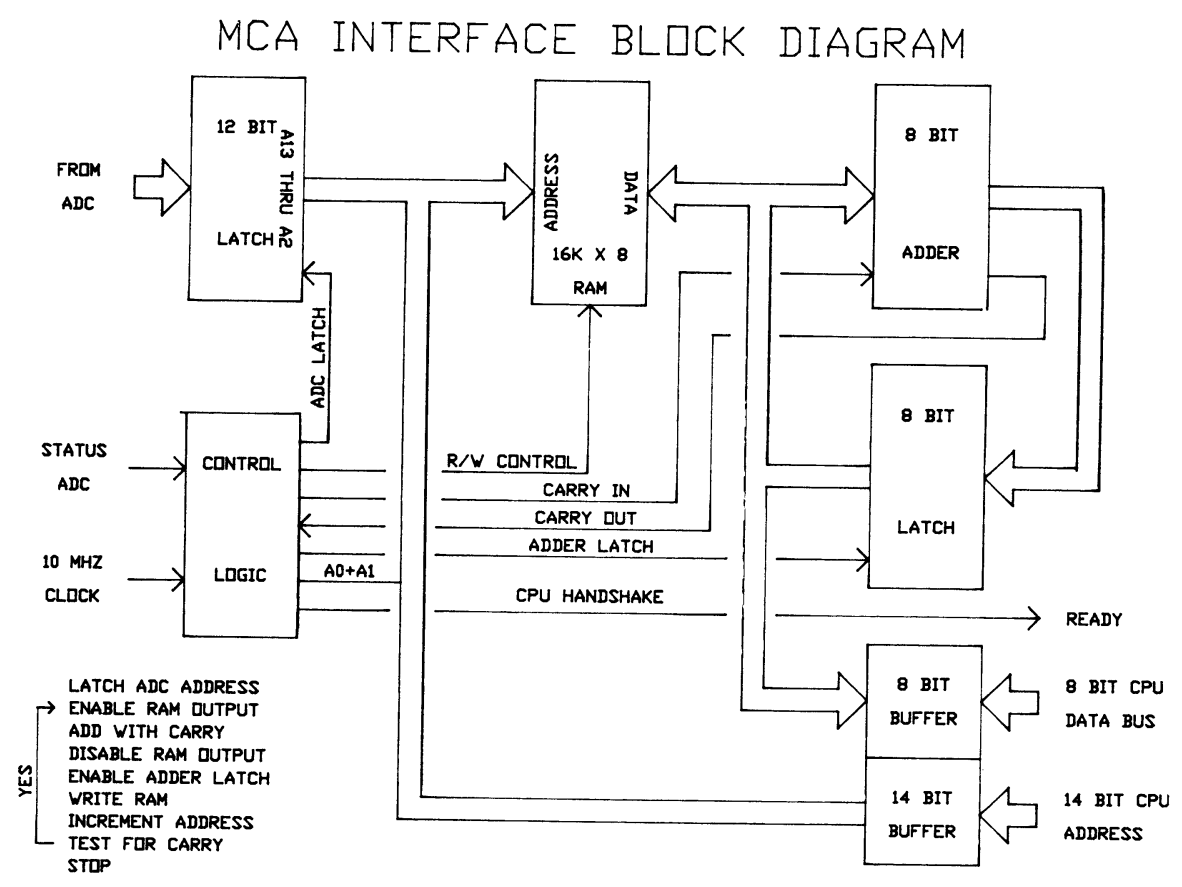

Fig 2. Block diagram of new MCA interface system

MCA memory could store a pulse in a maximum of $2.8 \mu$ seconds and so the CPU could access the MCA memory in between $A / D$ conversions even at high pulse rates. If a pulse arrived while the CPU was accessing the MCA memory, the A/D output would still be latched and handled at the end of the CPU access cycle.

\section{SOFTWARE DESCRIPTION}

The software on the Sanyo microcomputer consisted of five parts: counting parameter setup, remote control of sample changer, raw data transfer from LSC to disk file, graphic output of raw spectra and preliminary statistical calculations with output to LOTUS 1-2-3 compatible files. The counting parameter setup routine permits the user to set sample name for disk storage, automatic external standard (AES) count time, sample count time, maximum counts per sample for each sample in the sample tray and two independent counting windows. The count time resolution is $0.01 \mathrm{~min}$ with a maximum 999.99 -min interval. The maximum counts give the user an alternative method to stop the counting interval when a selected number of counts has been reached. In the counting windows, each channel represents a $0.5 \mathrm{KEV}$ step in energy. The maximum channel number is 4095 . 
The Sanyo microcomputer has software control over the samplechanging mechanism by a series of commands given to the Z-80 LSC interface which perform sample position selection, raising the sample into the counting chamber, AES source entry and AES source withdrawal. Any error detected would cause the routine to loop attempting to clear the problem. The same routine selects which sample is to be counted, programs the Z-80 with the counting interval, detects the end of the counting interval, calls the routine to store the data on disk files and continues on to select the next sample.

The data transfer routine uploads the raw data from the LSC by channel number. The channels within the counting windows are summed up and stored on disk under the sample name along the interval time and a flag to indicate whether it is an AES or normal counting interval. The same information is also printed out on the printer for each interval, tagged with the sample name. The entire raw spectrum is added to a separate disk file for retrieval when needed. The spectrum graphing routine plots out on the display the raw channel counts for the current MCA memory or for any previous spectrum stored on disk. Scaling of axis is automatic at first but can be overridden and set manually. There is an option to make a printout of the

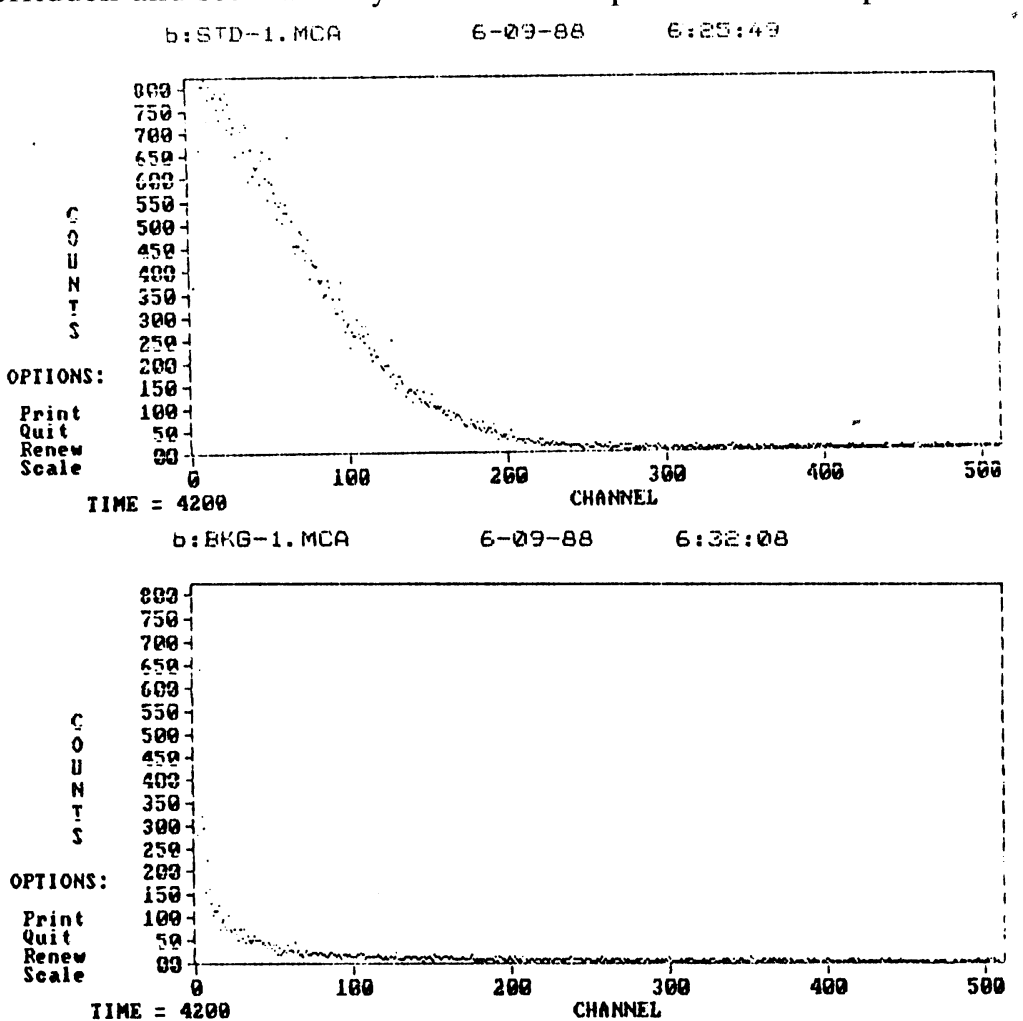

Fig 3. Printout of spectra for Oxalic Acid I standard and background by the software developed for this project 
screen. This permits the user to monitor the spectrum over many months, checking for possible sample preparation problems and errors in the counting electronics. Figure 3 shows a standard spectrum and background spectrum. The statistics routine reads in the stored interval data for the windows and calculates average cpm, standard deviation of cpm and Poisson limit for the average cpm. It prints out both the interval cpm, the

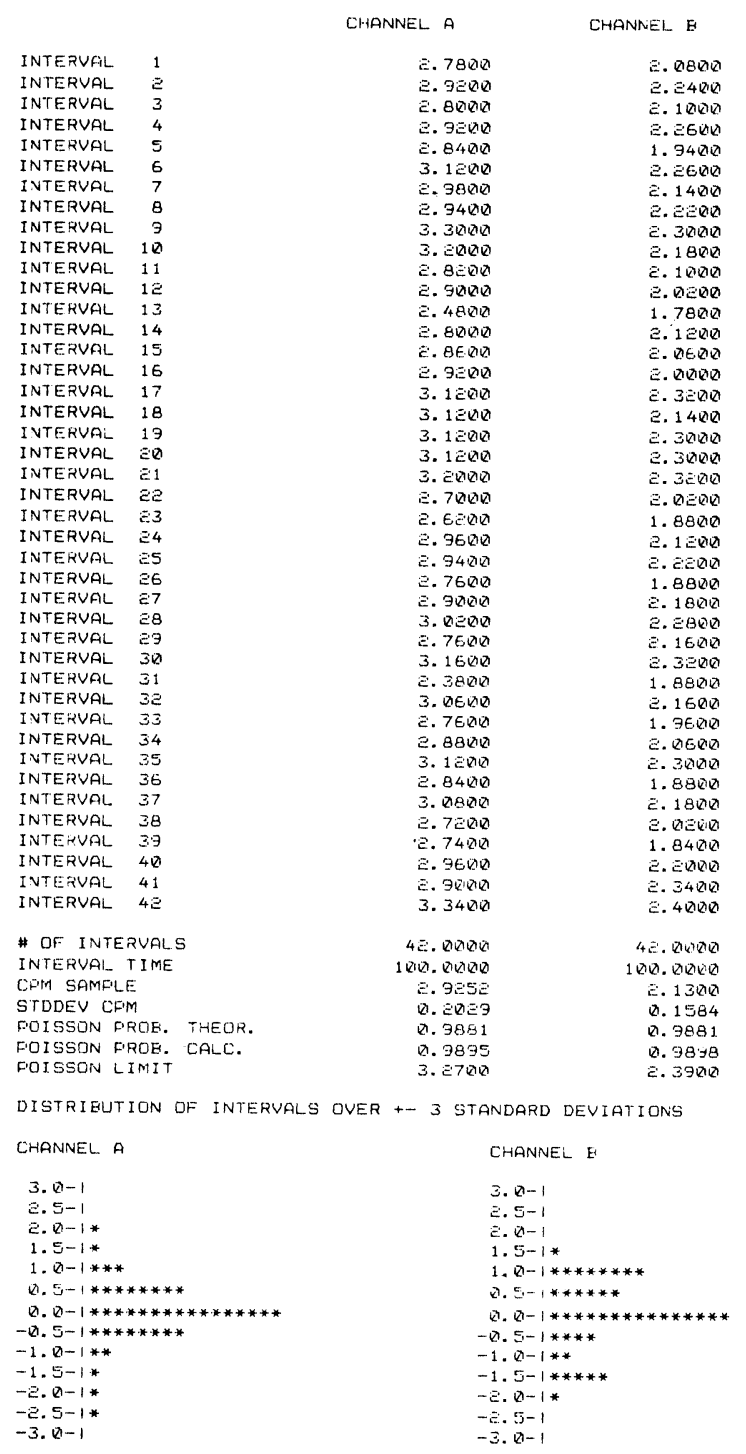

Fig 4. Printout of data from a background sample including the counts per minute and statistics for two energy channels as calculated by the software developed for this project 
calculated statistics and a distribution graph of the intervals (Fig 4 for background). Any intervals outside the Poisson limit are flagged and the user can edit them out. The routine is repeated until there are no rejected intervals. The results are then written to a LOTUS 1-2-3 compatible data file for use in age calculation.

\section{CONCLUSION}

It is possible to upgrade older LSC equipment to allow better sample monitoring and easier, more reliable operation. This upgrade is not only useful for ${ }^{14} \mathrm{C}$ counting, but also relatively inexpensive.

\section{ACKNOWLEDGMENTS}

The authors would like to thank the members of the University of Arizona Radiocarbon research group, in particular Austin Long, for discussion of this project, and the staff of the Department of Geosciences' electronics shop for their prowess in the construction of the MCA interface board. We would also like to acknowledge support by the State of Arizona.

\section{REFERENCES}

Bowyer, D E and Pearson, J D, 1973, A flexible FORTRAN IV program for scintillation counter data processing with optional features for user specific requirements, in Crook, M $\mathrm{A}$ and Johnson, P, eds, Liquid scintillation counting, vol 3, Symposium on liquid scintillation counting, Proc: Brighton, England, Heyden \& Sons, p 94-106.

Glass, D S and Woods, T L, 1970, A comparison of computer-input methods used to process liquid scintillation counting data, in Dyer, A, ed, Liquid scintillation counting, vol 1, Symposium on liquid scintillation counting, Proc: Brighton, England, Heyden \& Sons, p 79-95.

Gordon, B E, Press, M, Erwin, W and Lemmon, R M, 1976, An interface for routine spectral display from several liquid scintillation counters, in Noujaim, A A, Ediss, C and Wiebe, L I, eds, Liquid scintillation, science and technology: New York, Academic Press, p 173183 .

Noakes, J E and Valenta, R J, 1989, Low background liquid scintillation counting using an active sample holder and pulse discrimination electronics: Radiocarbon, this issue.

Polach, H A, Nurmi, J, Kojola, H and Soini, E, 1983, Electronic optimisation of scintillation counter for detection of low-level ${ }^{3} \mathrm{H}$ and ${ }^{14} \mathrm{C}$, in McQuarrie, S A, Ediss, C and Wiebe, L I, eds, Advances in scintillation counting: Alberta, Univ Alberta Press, p 420-441.

1984, Multiparameter liquid scintillation spectrometry, in McQuarrie, S A, Ediss, C and Wiebe, L I, eds, Advances in scintillation counting: Alberta, Univ Alberta Press, p 508-525.

Polach, H A, 1987, Evaluation and status of liquid scintillation counting for radiocarbon dating: Radiocarbon, v 29, no. 1, p 1-11.

Spratt, J L, 1972, Acquisition and handling of liquid scintillation counting data, in Crook, M A, Johnson, P and Scales, B, eds, Liquid scintillation counting, vol 2, Symposium on liquid scintillation counting, Proc: Brighton, England, Heyden \& Sons, p 245-265.

Stanley, P E, 1972, Determination of absolute radioactivity in multi-labelled samples using external standardization or channels ratio: a FORTRAN IV program, in Crook, M A, Johnson, P and Scales, B, eds, Liquid scintillation counting, vol 2, Symposium on liquid scintillation counting, Proc: Brighton, England, Heyden \& Sons, p 285-291. 1976, in Noujaim, A A, Ediss, C and Wiebe, L I, eds, Liquid scintillation science and technology: New York, Academic Press, p 209.

Williams, M A and Cope, G H, 1970, The processing of liquid scintillation spectrometer data using a desk-top computing system, in Dyer, A, ed, Liquid scintillation counting, vol 1, Symposium on liquid scintillation counting, Proc: Brighton, England, Heyden \& Sons, p 69-78. 